\title{
Project Management in the Fourth Industrial ReVolution
}

\author{
António Cabeças, Mário Marques da Silva \\ Universidade Autónoma de Lisboa, Portugal
}

\section{KEY WORDS}

Fourth Industrial

Revolution

Project Management

Green Project

Management

Sustainability

\begin{abstract}
The Fourth Industrial Revolution (also referred to as Industry 4.0) is driven by a massive utilization of new technologies, such as robots, artificial intelligence, Internet of Things (IoT), Big Data, Quantum Computing and Quantum Communications, replacing humans by machines in certain tasks or the development of new or more efficient tasks. The Fourth Industrial Revolution is originating huge modifications in society and organizations. Human adaptation to the new paradigm is required, as it will have a high impact on jobs and on the required skills. Project Management has evolved significatively in the last decades, privileging the fulfilment of the scope, time and cost of projects, based on the "triple constraint" classic model, and is still evolving due to the needs of new projects in the Fourth Industrial Revolution. This evolution has taken us to more complex models, with greater concern for the benefits that a project will bring to society and environment, which is a great challenge for Project Managers.
\end{abstract}




\section{Introduction}

$\mathrm{U}$ sing robots and artificial intelligence, the Fourth Industrial Revolution is already deeply modifying society and organizations (Kunze et al., 2018). As can be seen in Figure 1, the Fourth Industrial Revolution comprises other parameters than only robots and artificial intelligence (Griffiths and Ooi, 2018). Robots need to communicate and to sense the environment (using sensors and communications), for which Internet of Things ${ }^{1}$ is utilized. IoT generates massive quantities of data (big data) that will be processed with artificial intelligence to generate knowledge, i.e., to support the decision making or to make decisions using robots (Mariani, 2017).

Figure 1. The Context of the Fourth Industrial Revolution

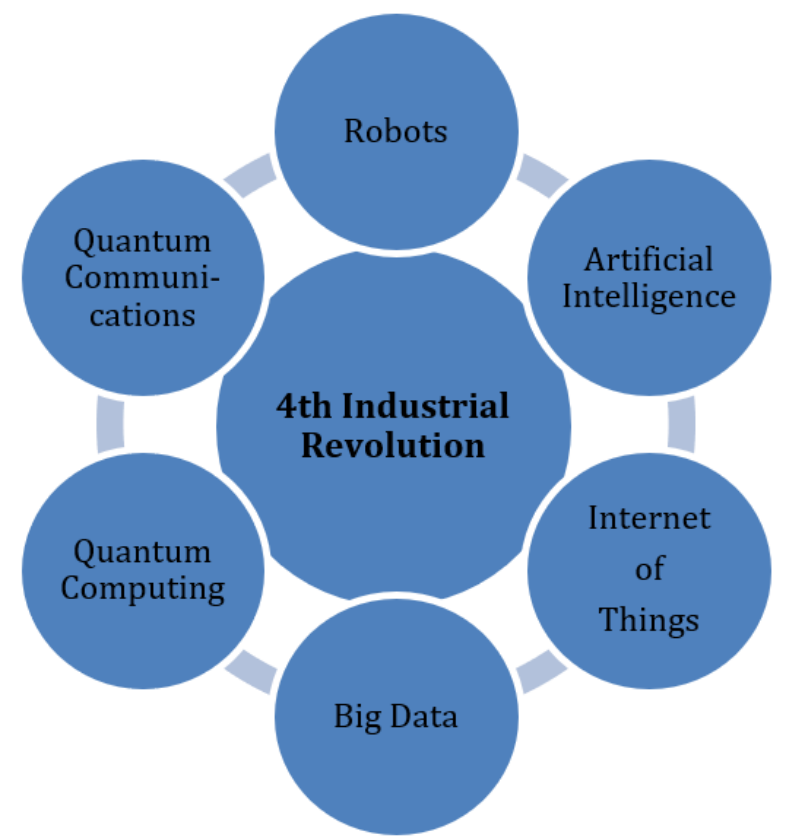

Source: Adapted from Author, 2020

These new technologies will originate a deep change in society, with high impact on the way we live, on organizations, as well as on the employment market.

The first profound change in the way we live took place 10,000 years ago, when, thanks to the domestication of animals, humans stopped

\footnotetext{
${ }^{1}$ All data is transmitted over the IP Protocol, while machines communicate, instead of people.
}

searching for food and started agriculture. The agricultural revolution was followed by several other industrial revolutions that started in the second half of the 18th century, which can be defined as:

- First Industrial Revolution (1760 to 1840): use of the steam engine in industry and in the railways;

- Second Industrial Revolution (18501945): use of electricity and introduction of assembly lines;

- Third Industrial Revolution (1950 to 2000): digital revolution and media era, as well as information systems and technologies.

Like the Third Industrial Revolution, the Fourth Industrial Revolution will make some jobs disappear and others appear. Also, as before, new and higher levels of skills will be demanded to face the new environment. Instead of having the previously described transforming view of employability, some people have a very pessimistic view, forecasting that most jobs will be replaced by robots, leaving most people unemployed (Rainai and Kocsis, 2017). Nevertheless, similar pessimistic view of the Third Industrial Revolution was foreseen by some people, but the reality proved that employment simply changed. rather than suffer a chaotic impact. While replacing repetitive human activities and reducing the risk of accidents (e.g., professional or car accidents with autonomous cars), robots will bring added value to elderly people and those with disabilities (Marques da Silva, 2019). Nevertheless, like other technologies, negative outcomes and impacts will depend on peoples' values and way of use.

Project Management has existed since man began building in an organized manner, and there is evidence that in older civilizations there were already defined and followed rules in the construction of buildings and roads. In ancient civilizations (Greek, Egyptian, Roman, Asian and pre-Columbian American civilizations), the need to build accurately, according to established plans, respecting defined costs and deadlines, clearly indicates a concern with Project Management (Cabeças, 2018).

Frederick Taylor (1856-1915) was one of the pioneers of management techniques applied to 
industry, having published. in 1911. the book "Principles of Scientific Management", considered a reference in this area. Henry Gantt (1861-1919), a disciple of Frederick Taylor, is considered one of the most important drivers of planning techniques and project control, having become known for his use of bar charts as a support tool for Project Management, now called "Gantt Charts". He was the first to use milestones for deliverables, task duration, and estimates. Although improved with more recent techniques, such as dependency definitions, the essence of content and format, Gantt Charts have remained virtually unchanged for 100 years. But it is consensual to consider that, in the 1950s, when the modern era of Project Management began, with the development of the PERT and CPM models, currently known as PERT/CPM 2 (Cabeças, 2018).

In 1967, the International Project Management Association (IPMA) was founded in Europe, bringing together project management associations from various European countries. In 1969, the Project Management Institute (PMI) was created in the United States of America, with the aim of finding ways to improve Project Management. PMI started the development of the Project Management Book of Knowledge (PMBoK), which defines the standards and practical guidelines for Project Management, which quickly became one of the main guides in this area, followed worldwide (Cabeças, 2018).

Thus, according PMBoK, Project is a temporary effort carried out with the objective of creating a specific product or service; Project Management was defined as the application of knowledge, skills and techniques to design activities aiming to achieve or exceed the needs and expectations of the parties involved with regard to the project. Project Management presupposes the existence of Project Managers, who must have the appropriate professional qualifications and profile to be able to manage a project (PMI, 2013).

The European Commission developed $\mathrm{PM}^{2}$ in 2007 for application to EU projects and, in 2012, the ISO 21500 Standard was issued, with a generic guideline and description of the

\footnotetext{
2 Program Evaluation and Review Technique (PERT) and Critical Path Method (CPM)
}

fundamental principles for good practices in Project Management.

This paper is organized as follows: section 2 describes the Impacts of Industry 4.0, while section 3 describes Evolution of Project Management in the Scope of the Fourth Industrial Revolution. Finally, section 4 concludes this paper.

\section{Impacts of Industry 4.0}

Schwab, K. (2016), the President of the World Economic Forum, stated the following about the Fourth Industrial Revolution: "The changes are so profound that, from the perspective of human history, there has never been a time of greater promise or potential peril".

The way we interact is undergoing profound and rapid changes, with an impact on the family environment, friendship and on the different relationships, as a result of multi-contact (Marques da Silva, 2019). However, there tends to be a progressive loss of freedom, with greater social exposure, and there is the risk that some people become slaves of technologies, rather than use them to make their lives easier. Depending on how people, organizations and countries manage technologies made available by the Fourth Industrial Revolution, several impacts can occur (Marques da Silva, et. al., 2018):

- Improvement of employability, with fewer hours of work per week and enhancing teleworking;

- Improvement of Communication and mobility, reducing distances and contributing to Globalization;

- Democratization of resources, information and knowledge, and an education more personalized to individual needs;

- Increased life expectancy and quality of life and well-being;

- Better autonomy and quality for people with disabilities and chronic diseases, as well as elderly people;

- Greater participation of individuals in social activities.

Robotization tends to facilitate everyone's domestic and routine activities, using devices such as smart vacuum machines or kitchen robots. The availability of new technologies will 
enhance the creation of new devices that will continue to act as facilitators for the average person, as well as for the most vulnerable, such as the disabled or the elderly. One of the limitations of the elderly with mobility difficulties is the difficulty of acquiring food. A smart refrigerator, with Internet of Things, which makes automatic purchases over the Internet when the food stock drops below a certain threshold, will be a great facilitator. This functionality will tend to be extended to the smart kitchen, rather than the simple smart fridge (Marques da Silva, 2019).

Industry 4.0 is deeply modifying society and organizations in several areas, as detailed in Figure 2. This includes a more efficient mobility based on self-driving cars, smart cities, intelligent industries, medical and lawyer counselling, the use of intelligent drones for a myriad of areas, including in defence, etc. (Zhou et al., 2015).

Figure 2. Potential areas modified by the Fourth Industrial Revolution

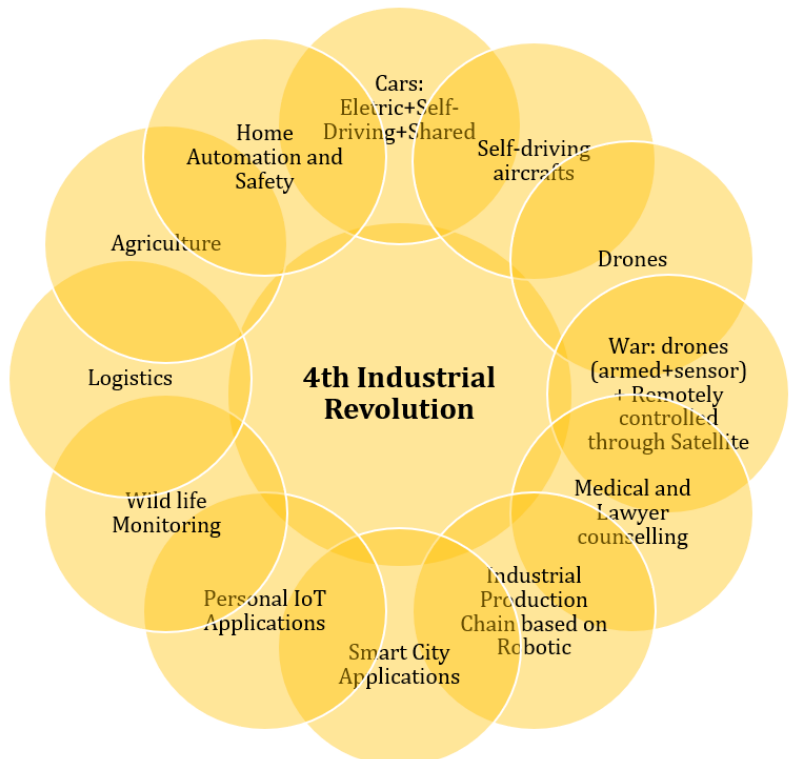

Source: Adapted from Author, 2020

According to Schwab, K. (2016), the Fourth Industrial Revolution is different from previous revolutions in terms of:

- Velocity: It evolves at an exponential and non-linear pace. This is the result of the multifaceted and deeply interconnected world in which we live. In addition, new technologies generate newer and more qualified ones;

- Amplitude and depth: It is based on the digital revolution and combines several technologies, leading to unprecedented paradigm shifts in economy, business, society and individuals;

- Systemic impact: It involves the transformation of entire systems between and within countries, into companies, industries and across society.

We are experiencing a new reality with a systematic and profound change, which recent examples from companies such as Airbnb, Uber, Alibaba, Google (autonomous car) or WhatsApp, help to illustrate. Goodwin (2015) said that "Uber, the largest taxi company in the world, does not even have a vehicle. Facebook, the world's popular media owner, does not create any content. Alibaba, the most valuable sales site, has no stocks. Airbnb, the largest hosting provider in the world, doesn't even own a property.".

Besides the change of paradigm in the way businesses are implemented, the Fourth Industrial Revolution contributes to a more efficient use of resources. Uber helps optimizing the use of cars, while Airbnb helps optimizing the use of properties.

Massive use of self-driving cars boosts their sharing, which translates into more efficient mobility and more efficient use of resources. Therefore, instead of using a car for a short percentage of time, while the car is getting older, the sharing of cars is expected to be the future of mobility (Febbraco et al., 2019). Therefore, either one purchases a car and shares it with others, while not in use, or one simply uses a car that is shared by someone else. This view is reinforced because, with self-driving cars, driving license is not required, and the risk of accident is much reduced, as compared to current cars.

$5 \mathrm{G}$ communications play an important role in autonomous driving using the mode Ultrareliable Low-latency Communications (URLLC). As can be observed in Figure, URLLC was designed to support new services, such as remote surgeries or autonomous vehicles, services that are delay sensitive and that require 
a very low bit error rate (errors are almost unacceptable). Therefore, URLLC is about highspeed, low-latency vehicle-to-vehicle communications (V2V), in addition to conventional communications through a base station. 5G, using millimetre waves, i.e., frequencies of around $60 \mathrm{GHz}$ (RAPPAPORT, T.S. et. al. (2013)), will allow rapid sharing of large amounts of information in V2V communications, such as position, course, speed, position of origin and destination of the trip, surrounding traffic, etc. (Marques da Silva, 2019).

MIMO system (multiple transmit and receive antennas) consists of a technology that, alongside with millimetre waves, supports the demanding requirements of $5 \mathrm{G}$ communications. This allows an exponential increase in transmission rates through the exploitation of multiple parallel flows of data (tens, hundreds or even thousands of times higher) between each transmit and each receive antenna (Marques da Silva, M., and Monteiro, F. (2014)) (Marques da Silva, and Dinis, M. (2017)). In addition to autonomous driving, 5G, through Internet of Things, will boost the implementation of smart cities, remote surgeries, virtual reality, smart logistics, etc. As can be seen in Figure 3, Massive Machine-type communications (mMTC) is the mode that supports Smart Cities, by implementing Internet of Things using massive quantity of devices that send low amounts of data, and using low power levels. Finally, Enhanced Mobile Broadband (eMBB) mode aims to provide wide coverage using a base station. Note that $5 \mathrm{G}$ will be implemented in different phases: the first phase comprises eMBB, as defined by $3 G P P$ release 15 , while URLLC and mMTC are defined in 3GPP release 16 , to be implemented in a later stage.

Figure 3. The Three 5G Use Cases
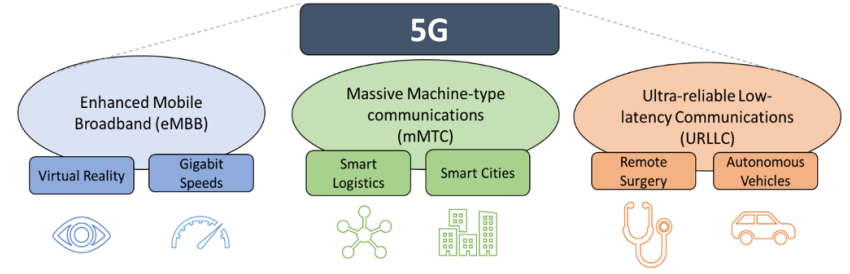

Source: Adapted from Author, 2020.
While human, social and organizational efficiency tends to improve with the fourth industrial revolution, human freedom needs to be maintained, and special attention should be paid to the new ethical issues that arise. Regulation plays a fundamental role, as well as the correct individual and organizational use of technologies, so that they act as facilitators to human lives and organizations, instead of making them slaves to these technologies (Marques da Silva, 2019).

\subsection{The Employment Market in the Context of Industry 4.0}

Some more pessimistic analyses present a view that the substitution of humans by robots will result in a high level of unemployment. Similar fear occurred with the third industrial revolution, which was not experienced. Others believe that the Fourth Industrial Revolution will lead to the disappearance of some jobs, but to the appearance of others, while a higher level of skills is required (Marques da Silva, 2019). A recent study undertaken by the Organization for Economic Co-operation and Development (OECD) indicates the following influences of the Fourth Industrial Revolution on employability (OECD, 2018):

- Automation mostly affects industry and agriculture, but the services sector is also vulnerable to automation;

- The greatest risk is found in the most routine jobs, with low qualifications and underpaid;

- About 14\% of existing jobs in OECD countries are highly automated, while $32 \%$ of jobs can undergo a substantial change in the way they are performed;

- The lowest risk is applicable to a wide range of jobs related to the creation, maintenance and administration of technologies, creative intelligence, organizational manipulation, as well as social intelligence, such as social understanding and personalized care for dependent people;

- Young people entering the job market are more vulnerable to automation 
than jobs held by more experienced people;

- Not all technically automated jobs will disappear. In addition, other jobs will be created, with the expectation that employability will continue to increase.

Bill Gates and Elon Musk have warned us about the job market issue, which has been discussed at the World Economic Forum, and that about five million jobs will be lost by 2020 in the main world economies, as a direct consequence of industry digitalization. Elon Musk thinks we must be very careful with the evolution of Artificial Intelligence (AI) or we will end up in a world dominated by "Google created killer robots". But Bill Gates does not agree with this view, considering that we have nothing to fear in the future. Mark Zuckerberg, creator of Facebook, and John Giannandrea ex-Google, now at Apple, agrees with Bill Gates, stating that humanity only has to benefit from the use and evolution of Artificial Intelligence.

Schwab, K. (2016), states that experts warn about the gap between rich and poor widening, as only those who are technologically well prepared will take advantage of this new revolution. Thus, solutions and new answers will be needed so that the risk of increased unemployment can be mitigated. There may even be new opportunities to mitigate this risk, as, according to a recent study by the International Labour Organization (ILO), between 120 and 150 new professional activities will emerge in the next 50 years, many of them generated by the technology itself.

\subsection{The Problem of Global Security}

Schwab, K. (2016) warns his readers that a hyper-connected world, with increasing inequalities, may lead to an increase in fragmentation, segregation and social unrest that, in turn, will allow for violent radicalism. This author also considers that cyber wars may arise, in which an adversary can disturb, confuse or destroy the sensors, communications and decision-making capacity of enemies, in which the traditional physical borders of countries will be irrelevant. Information Security relies on a set of controls, such as policies, legislation, processes, procedures, organizational structures, software, and hardware functions.

We live in an era when human beings are electronically controlled in different ways. They are controlled by banks through the movement of their credit cards, by telecommunication operators through the human use of the cell phone, by Internet Service providers, by social networks, by operating systems such as Android (Google) and iOS (Apple), by surveillance cameras installed in cities and streets, etc. Therefore, while the efficiency and level of security tends to be improved with new technologies, the freedom and confidentiality of data is in danger. There are already cities where surveillance cameras are associated to artificial intelligence. This allows a security system of a city to track each human, as well as his or her behaviour. Nevertheless, depending on the way information is managed and secured, human freedom and confidentiality can be at risk.

The new General Data Protection Regulation (GDPR), laid down in the European Union Regulation 2016/679, was published on 4 May 2016, and entered into force in 2018. This regulation aims to:

- Harmonize data privacy laws across the European Union (EU);

- Protect and enable all EU citizenship data privacy;

- Redefine how organizations across the region address data privacy.

Human behaviour, as well as organizational behaviour, in view of technologies is the key issue to define whether or not the latter bring added value to each person or organization. Are relationships more efficient and more human, do people feel closer to one another, are they happier? In the past, a process that was managed via two or three letters is now managed using several dozens of e-mails, with much unstructured information. Handwriting and mental multiplication tables are getting lost and dyslexia is increasing as a result of the widespread use of technology. Therefore, technology can make people slave to machines but, on the other hand, it may improve human, social and organizational efficiency, and fight poverty, disease and ignorance. It depends on the way we use technology. 10 USD smart Phones 
are reaching the poorest countries in the world, eliminating asymmetries, massifying the use of technologies, information and knowledge, and therefore, reducing inequalities. It is worth noting that, as result of higher level of dependency on technologies, Industry 4.0 tends to make companies more capital intensive. This is increasing the asymmetries between small and big companies.

In addition to changes in growth patterns, labour markets and the future of work, there is evidence that Industry 4.0 technologies represent a major impact on how companies are led, organized and managed, with the following impacts:

- Customers' expectations are changing;

- Products are being improved by data, which improves asset productivity;

- New partnerships are being formed, as companies learn the importance of new forms of collaboration;

- Operational models are being transformed into new digital models.

Using artificial intelligence, medical and legal counselling tends to be more efficient and more effective when provided by computers, instead of humans, reducing the risk of errors. Surgery tends to be more effective, and with lower level of risks, when performed with the support of robots. On the other hand, wars tend to be more technology dependent, using drones, armed with sensors, controlled through satellite, and remotely operated from other parts of the globe. In the case of a tactical war, a micro-drone can play an important role by increasing surveillance, while minimizing the risk to the troops involved.

One can imagine a micro-drone, equipped with a camera, with artificial intelligence, and armed. What could be the impact of using thousands of these micro-drones in a city, to perform a specific and autonomous attack? What if a terrorist organization could create and use such micro-drones? While the conventional war is protected by international agreements and national legislation, new technologies originate a change in paradigm. Nowadays, the nuclear weapons non-proliferation treaty controls the development of nuclear weapons. Nevertheless, new technologies, such as micro-drones, armed, and equipped with artificial intelligence, can be similarly dangerous, but much easier to be implemented, and therefore easily out of control.

Current Microsoft President Brad Smith said at the 2017 Web Summit that cybersecurity must be one of the great causes of our time. Cybersecurity is the term used for the means and technologies used to protect networks, computers, programs, files and data, in response to cybercrime. Information security and data security must be guaranteed, as these are very important assets for any organization, knowing that information security also involves, processes and people, not only technology, and it is required to implement an appropriate set of controls, including policies, processes, procedures, organisational structures, software and hardware functions.

The new risks that arise from the use of new technologies by terrorist organizations originate a shift in paradigm, and global control, instead of control limited to the borders of a country. This is only possible with a collaborative attitude among different countries, instead of the simple and usual competitive attitude.

\section{Evolution of Project Management in the Scope of Industry 4.0}

As mentioned before, Project Management has existed since humans began to build in an organized manner, but only in the late 19th and early 20th century, Frederick Winslow Taylor (1856-1915) applied scientific reasoning to the work, demonstrating that manpower can be analysed and perfected. He applied his reasoning to routine tasks performed in factories and, to improve productivity, he introduced the concept of working more efficiently instead of working longer hours, focusing on the organization of production processes and training. Henry Gantt (1861-1919) was one of the most important drivers of project planning and control techniques, having become known for the creation of the famous "Gantt Charts". It is consensual to consider that it is in the 1950s that the modern era of Project Management begins, models PERT and CPM were developed at that time, later called PERT/CPM by its joint use. In 1967, the International Project Management 
Association (IPMA) was founded in Europe and, in 1969, the Project Management Institute (PMI) was established in the United States of America, with the aim of finding ways to improve Project Management. In 1981, PMI started the development of the PMBoK, which defines the standards and practical guidelines for Project Management, which quickly became one of the main guides in this area, followed worldwide. The European Commission developed PM2 in 2007 for application to projects within the European Union and in 2012 the ISO 21500 Standard was issued, with a generic orientation and description of the fundamental principles on best practices in Project Management.

\subsection{Recent developments in Project Management}

The classic model of Project Management, known as Triple Constraint, considered that if a project was completed in the planned time, with the expected cost and the agreed scope, it would be a quality project and, if it met the expectations of its Stakeholders, it would succeed. This model may be represented by figure 4 .

Figure 4. Triple Constraint

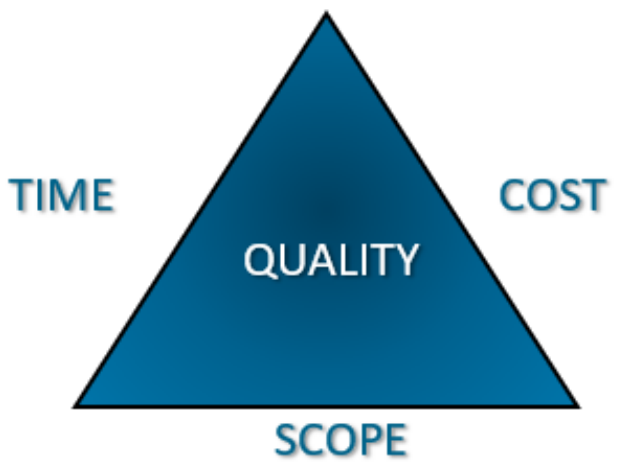

Source: Adapted from Author, 2018

In this model it is considered that a project has quality if time, cost and scope are achieved. Kerzner (2006), an American engineer known for his work in the areas of Project Management, states that at the beginning of the application of the techniques and concepts of Project Management, concerns were strongly oriented towards cost and time risks. From the 80's on, companies began to feel the need to work with risks through their impact on scope, cost, time and quality objectives.

The PMI report "Pulse of the Profession 2018 - Success in Disruptive Times" refers, based on rigorous statistical studies, three "top drivers" for the success of a project:

1. Investing in the active involvement of executive Sponsors;

2. Avoid increasing the scope or unchecked changes in the project scope;

3. Mature capabilities for value delivery.

Recent PMI statistics confirm that more than $50 \%$ of projects that fail are due to communication problems, poor planning and setting unrealistic deadlines.

Kerzner (2014) asked during an interview the following question: "You only get value from a project when it adds something positive and meaningful to the business, but how many projects add value?". If a project does not add anything to the business and society, it can be considered a useless project, since, currently, the goals of a business are also being seen from other perspectives besides the traditional profit, such as ethical and sustainability perspectives that are now being considered even more important.

The development of sustainable projects has become increasingly important for organizations. ISO 26000 defines sustainability as "integrating the goals of a high quality of life, health and prosperity with social justice and maintaining the earth's capacity to support life in all diversity", so organizations have to develop new projects in a sustainable perspective with respect to stakeholders' expectations on social responsibility (IPMA, 2016).

It is also important that Project Management is aligned with the organizations' strategy, and strategies should be understood and transformed into elements that can be managed through projects. In this sense, a management system is being defined, in which projects are seen and managed in light of their alignment with organizations' strategy and vision, ensuring their high correlation with the organization's mission and sustainability (IPMA, 2015).

Green Project Management (GPM) is defined as a model in which we think about our project with an environmental concern, making 
decisions that consider their impact on the environment. It is a way of thinking green in each of the five Project Management Process Groups ${ }^{3}$, from a sustainability perspective, defined as supporting some condition, something or someone in some process or task, with good use of natural resources, with strong concern for the environment and welfare. GPM Global, based in the USA, considers the evolution of this traditional model to a more complete one, in which new components are added, besides the traditional ones of Triple Constraint, according to the perspective represented in figure 5 .

Figure 5. GPM Global Model

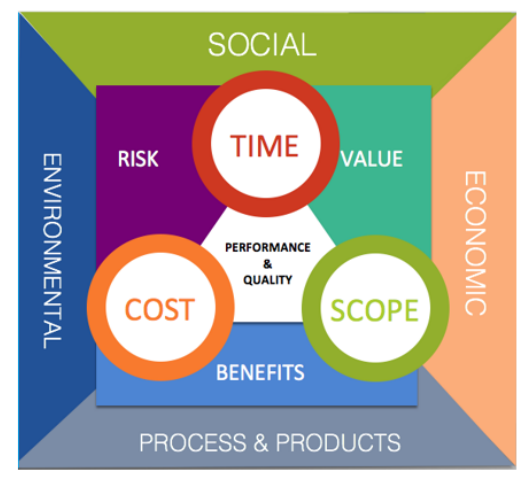

Source: GPM, 2019.

In this model, GPM Global (2019) considers that Project Managers should focus on time, cost, quality, scope, benefits and risks, and should also consider the five "P's", which are referred to in the document "The GPM P5TM Standard for Sustainability in Project Management", People, Planet, Prosperity, Processes and Products, highlighting their importance to achieve good Project Management and the creation of sustainable projects.

All these issues arise as a consequence of ongoing movements in a global society, increasingly based on a process of globalisation, and it is important to ensure that projects are truly sustainable, in which they not only contribute to meeting the needs of their stakeholders, but also add value to the environment and to society as a whole.

\footnotetext{
${ }^{3}$ According to the PMBoK, the five Project Management Process Groups are Initiating, Planning, Executing, Monitoring and Controlling, and Closing.
}

\subsection{Project Management Technology Quotient}

PMI Pulse of the Profession (PMI, 2019) mentions that, in a $2019 \mathrm{PwC}$ survey, in which a significant sample of CEOs participated, $85 \%$ of the respondents believe that artificial intelligence will significantly change the way they do business in the next 5 years, as well as mentions the importance of the Project Management Technology Quotient (PMTQ). QT is Technology Quotient, referring to a person's ability to adapt, manage and integrate technologies based on the needs of the organization or project in question. People and companies seek digital sustainability as the ability to adapt to the constant whirlwind of change caused by advances in technology. Associated with the changing nature of work from "lifetime employment" to "project portfolio", we see a greater demand for QT combined with Project Management, and the QTPG is emerging. For those responsible for making business strategy a reality in a world constantly changed by technology, the QTPG will be a set of compulsory skills to define success or failure (PMI, 2019).

According to PMI (2019), regarding the approaches used by PMTQ Innovators Versus the PMTQ Laggards, represented in figure 6, we may verify the importance of using PMTQ in a variety of project management approaches, such as Change Management, Hybrid Project Management practices, Design Thinking, Agile and DevOps. ${ }^{4}$

\footnotetext{
${ }^{4}$ DevOps is the combination of development and operations, being a software engineering practice that aims to unify software development (Dev) and software operation (Ops).
} 
Figure 6. Approaches Used: PMTQ Innovators Vs the PMTQ Laggards

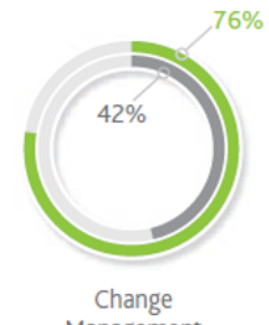

Management

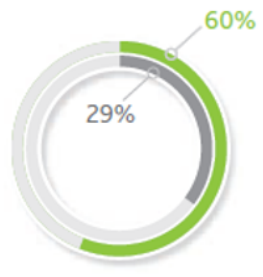

Hybrid Project Management Practices

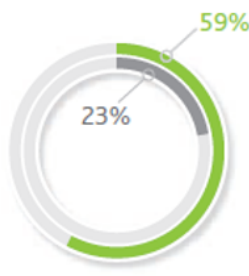

Design Thinking

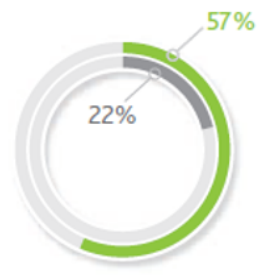

Agile

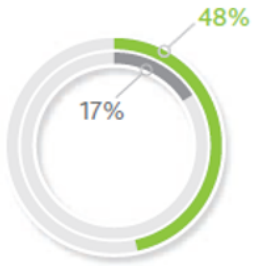

DevOps

a PMTQ Innovators $\quad$ PMTQ Laggards

Source: PMI, 2019.

In figure 7 we can see some of the process and project management capabilities that show what PMTQ Innovators rely on, which is a quite different path from the PMTQ Laggards, emphasizing, as examples, priority development of project management technical skills, providing ongoing project manager training and prioritize development of project management business skills.

With the information in figure 8 we may also confirm that the PMTQ innovators have better projects performance metrics, enhancing as significative examples, meeting $f$ the original project goals, the projects budget and the time planned for the projects.

Organizations that are PMTQ Innovators are better prepared to take the lead on project outcomes. This not only means PMTQ Innovators save money and improve stakeholder's satisfaction rates, but also that the percentage of project investment wasted due to poor project performance is less than the PMTQ Laggards (8.5\% versus $16.3 \%)$. Their projects are more likely to meet their original goals and be delivered on time and within budget while reducing scope creep and outright failure, leading to success (PMI, 2019).

Figure 7. Processes and Capabilities: PMTQ Innovation Vs the PMTQ Laggards

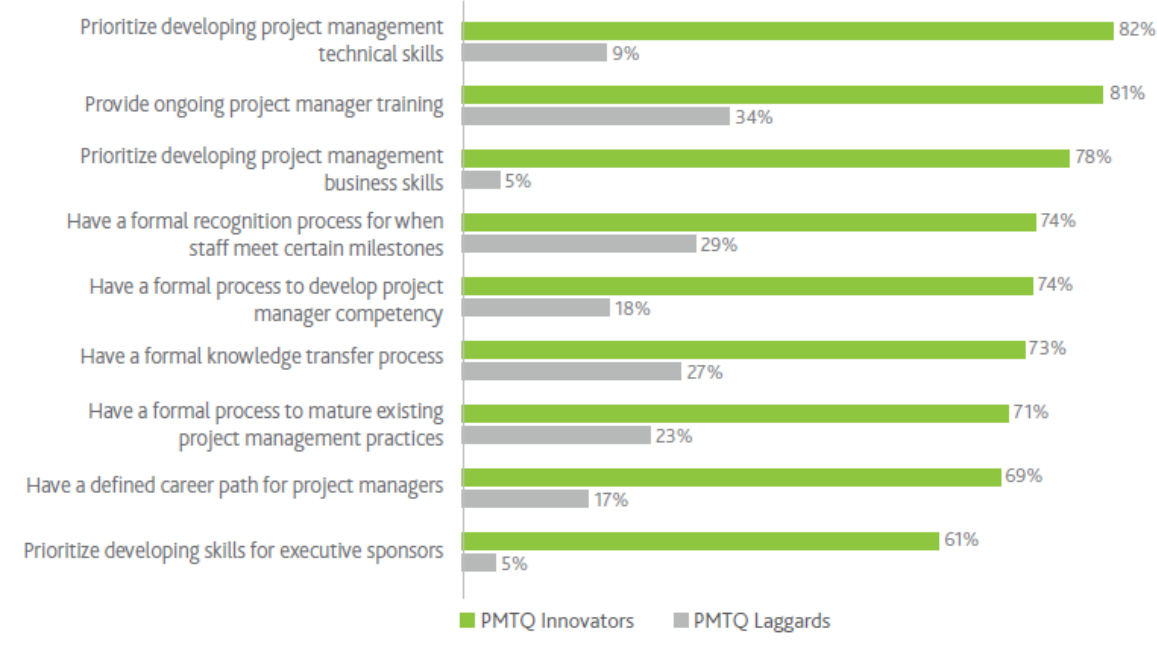

Source: PMI, 2019 
Figure 8. Project Performance Metrics: PMTQ Innovation Vs the PMTQ Laggards

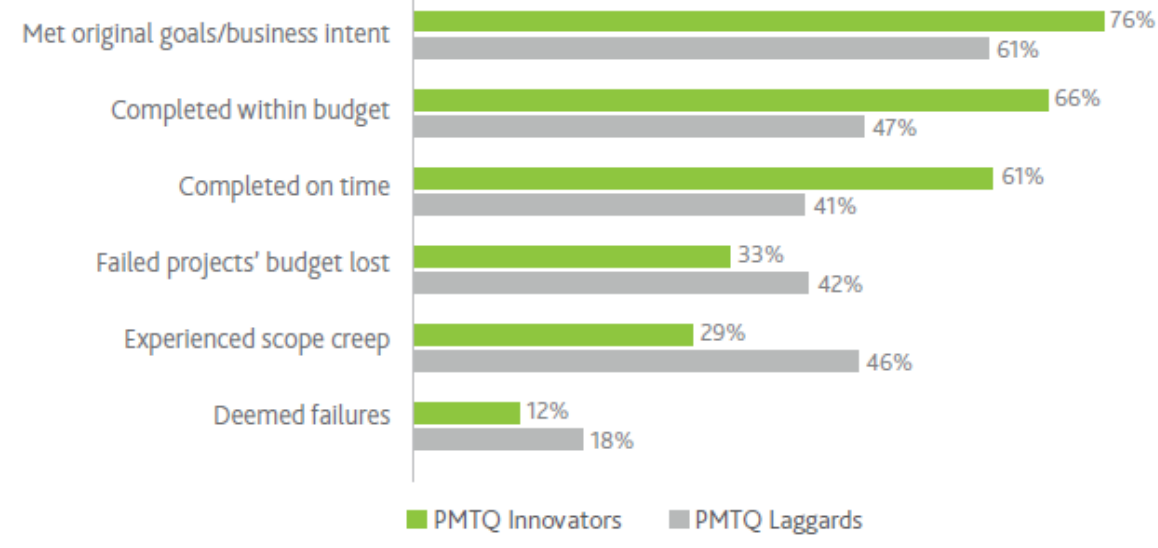

Source: PMI, 2019

\subsection{The evolution of Project Management}

The demands of connected and digital organizations operating in disrupted and rapidly changing landscapes, dominated by challenges of integration speed, are applying new levels of challenge to project and program management across the world (KPMG, 2019).

The methods and tools used in Project Management tend to evolve in view of the needs of projects associated with new technologies and with the use of Artificial Intelligence. It is unanimous that the tools used to support Project Management will evolve and will be more intelligent and sophisticated, and in addition to the planning and control components of the projects include functionalities to improve information sharing. The tools to support Project Management have evolved and there is an increasing supply in this area, and the evolution of Project Management models, whether traditional Waterfall or Agile project approaches ${ }^{5}$ are also following the technological evolution. Larger volumes of data (big data) will be available for analysis and sharing and many of the routine tasks Project Managers perform today will be automated.

KPMG (2019), based on a collaborative research survey undertaken in Australia in 2018, extended in 2019, with the assistance of IPMA and AIPM, to the global membership base of IPMA and associated regional partners, along

\footnotetext{
${ }^{5}$ Scrum, Kanban and Lean are some samples of Agile approaches.
}

with select KPMG client representatives, refers the following several key topics that are emerging or continuing to grow related with Project Management:

- Project management is being increasingly used to drive organizational strategy and success and has moved beyond merely delivering outcomes for business to pick up and adopt;

- The overall sense of success rates of projects continues to be low when viewed through the lens of cost, time, scope and stakeholder satisfaction;

- The importance of sponsorship in the project eco-system continues to be a key factor in project success;

- Collaboration software usage is increasingly being recognized as important in assisting in complex and large projects and has a link to success;

- Opinions remain divided about the effectiveness of enterprise wide PMOs;

- The use of Agile approaches is becoming more widespread;

- Change management is an increasingly important skill and knowledge area for PMs; and

- Project management as a skill continues to grow in importance.

The skills and areas of project management are being used to face business challenges. In time project delivery is essential for the modern organizations as a tool for delivering strategic change and driving bottom line performance 
improvement. Increasing focus on closing the gap between business needs and project delivery, through the application of Agile approaches, appear to be on the increase to further address these deficiencies. Also, there is evidence that engaged senior stakeholders have a significant positive impact on the likelihood of project success. Increasingly, Agile and adaptive approaches to deliver strategic outcomes through projects and programs require quicker and more insightful leadership from the Project Management Offices (PMO). It is also important to mention that automation, data analytics and artificial intelligence are increasingly offering new and improved ways of monitoring performance, identifying deviations from plan and underlying risks and issues (KPMG, 2019).

According to KPMG (2019) inquiry data it was possible to verify that the use of recognized project management software, tools and techniques is widespread, showing that $71 \%$ of organizations reported using project management software to improve the management and control of programs and projects. Specifically, 39\% are using specialist PM software, $20 \%$ are using an inhouse solution, while the remaining $12 \%$ are using non-PM commercial software. MS Project/Project Online is the tool used most readily. The level of maturity in development and use of software is generally identified as being 'operational' by close to half of all organizations. Usage of collaboration software is significant, with $51 \%$ of organizations using collaboration tools to support project delivery. At this stage, only $8 \%$ of organizations globally reported using Artificial Intelligence tools to support their projects. Based on this survey data, KPMG (2019) also identifies, that Agile delivery approaches are in use in over $47 \%$ of the inquired organizations, which represents a significant increase, highlighting its importance.

It is a fact that the tools to support the activities of Project Management have also evolved a lot in recent years, and there is an increasing supply in this area. MS Project continues to be the most used tool in Project Management, but in recent years other tools have appeared, like the best-known Jira and
Trello. There are also other tools ${ }^{6}$, that have appeared in the last few years, some of which with strongly information-sharing oriented and new tools will certainly continue to appear and all will be subject to "Digital Darwinism", seen as a natural selection process by their clients (organizations and Project Managers), but only the best will prevail. Artificial Intelligence, defined by Ford (2015) as the replacement of human decision making, imitating the human thought-process and allowing the machine to learn as a human being, will contribute to the improvement of these tools. More data will also be available for analysis and sharing, and many of the routine tasks that Project Managers perform today will be automated.

According to GPM Global (2019), to achieve true digital sustainability in the new future of work, organizations will need teams "ready for everything" who know their technology and master the techniques and methodologies used to help the Project Management activity. Project Management will continue to evolve towards GPM Global, and Project Managers will have to adapt to a new reality that is emerging with the Fourth Industrial Revolution. Moreover, Innovative QTGP companies, which give priority to digital skills and knowledge, will be more successful in their projects (PMI, 2019).

In a recent Gartner publication, Henderson et al. (2019) reported that continuous delivery is driving more management leaders to connect strategic business investments aligned with diversified delivery, shifting delivery focus from time to value and PPM vendors that offer technology to support these ventures are better evaluated. According to these authors, the strategic planning assumptions are:

- By 2023, 80\% of organizations will have an enterprise project, program or product management office (PMO) focused on integrating digital products and programs;

- By 2021, at least $40 \%$ of large enterprise IT organizations will have completed their implementation of a product-centric approach;

\footnotetext{
${ }^{6}$ Other examples of existing tools are AirTable, Artia, Asana, Basecamp, Bitrix24, Clickup, GanttProject, Hibox, Hive, Liquidplanner, Monday, Notion, Operand, Pipefy, Podio, Runrun.it, Slack, Teamwork, Wrike, etc.
} 
- By 2023, $65 \%$ of organizations that moved to product-centric delivery will have embedded their digital product managers in a business area;

- By 2023, technology providers focused on artificial intelligence (AI), virtual reality (VR) and digital platforms will disrupt, and elicit a marked response from, the traditional providers within the project and portfolio management (PPM) market.

Wagner (2017), in a post published at IPMA website, mentioned that, for project management, the Fourth Industrial Revolution means an increasing number of new projects, an increasing importance of the management of such projects, with a different type of management, viewed as some kind of an "orchestration" or "facilitation". Projects are performed to enable the creation of innovative products and services, and they require a flexible and context-adaptive facilitation. People join for one project, dissolve and reassemble in a different composition. Teams are increasingly fluid and thus require a flexible style of organisation, like a nomadic tribe with tents or other hybrid organisations. The specialization of people working in projects requires them to acquire new skills in order to be attractive to the organisation and the leadership style will change as there are no dependent employees anymore but "co-workers".

\subsection{Evolution of Project Managers' Behaviour}

The truly successful Project Manager of the future will be more strategic than tactical, with an increased focus on working with business leaders to rapidly and incrementally deploy benefits to support the overall business strategy (KPMG, 2019).

Because of the Fourth Industrial Revolution and the evolution of Project Management itself, Project Managers will also have to adapt to the new reality. Bolick (2019), Professor at Northeastern University in Boston in the field of Project Management, summarizes that Project Managers can embrace digital transformation with four different approaches:

\section{Promote the agility of change}

The digital transformation is much more than the increase in computing power. Technological capabilities, internal resources and customer experiences are changing. The Project Manager must adapt to this new reality and will play a greater role in identifying value, facilitating creativity and increasing flexibility, serving as an agent of change and influencing multidisciplinary teams in organizations.

\section{Evolving intellectual capacity}

Digital transformation will require an evolution in leadership skills. By 2020, two of the top ten leadership skills will be cognitive flexibility and emotional intelligence. Aoun (2017), president of Northeastern University in Boston, considers that including these two characteristics in the list of the most important skills for 2020 highlights their importance. Leaders who can apply emotional intelligence and cultural awareness, demonstrating critical thinking and analysis, will be at the forefront of digital transformation and the Fourth Industrial Revolution.

\section{Consider the resource dynamics}

Project Managers should adopt the idea that the project teams that execute the strategy will not only be composed of traditional resources. Teams can be composed of existing and new talent, being multifunctional and using advanced robotics and computing systems. Project Managers will need to create teams with a balance of native knowledge and new experiences. In addition, the emphasis will be on open-mindedness, cognitive skills and emotional intelligence. These qualities will be much sought after by employers to make the efficient transition of available resources into a digitized workforce.

\section{Refining emotional intelligence}

Finally, the Fourth Industrial Revolution will require leaders to balance innovation and chaos with the stability of organizational processes. As more and more organizations adopt artificial intelligence and advanced robotics, leadership 
becomes less about people with titles and more about organic collaborative processes. This new dynamic requires that the management and leadership roles of a project overlap and are based on shared knowledge to mitigate organizational policies. The importance of relationships and emotional intelligence will continue to be critical for Project Managers as they facilitate the relationship, motivation and overall enthusiasm of organizations.

According to an article published by Melanima (2018), Project Managers must improve their skills and adapt to the needs of the market in order to be project managers in Industry 4.0. In the past, purely technical skills were essentially considered, but social skills are also essential for good professional performance and, increasingly, the ability to interpret data is important, stressing the importance of using Business Intelligence (BI), to allow you to have a greater knowledge of the internal and external environments, and thus increase the competitive advantage of organizations and the success of future projects. The role of project managers 4.0, in addition to having a technical profile within their area of competence, must have the ability to work on data (Method, Concept and Tool, data collection and modelling, using BI and/or Big Data), writing and mainly interpreting the data for decision making in a globalized corporate universe.

PPM leaders will apply more diverse combinations of PPM tools, capabilities and consulting services to support the needs of today's enterprises. Scaling digital business requires PPM leaders to adopt new approaches to strategic planning and execution and drive successful business transformation initiatives and programs. PPM leaders must adopt simplified ways to use multiple types of PPM tools to support both decision making and execution without introducing technology redundancy. The latest digital trends are presenting some clear challenges to the PPM market, and these challenges have yet to be met. There are new, emergent approaches to both strategic planning and execution requiring more innovative PPM technology. Demand for the latest digital technologies (e.g., artificial intelligence and robotic process automation in all enterprise software markets is also applying pressure to providers in the PPM market (Henderson et al., 2019).

According Henderson et al. (2019), digital technology challenges for the PPM market include the following issues:

1. Strategy-to-execution alignment and management

The alignment with the organization strategy is very important, and it is also mentioned by KPMG (2019), IPMA (2019), Bolick (2019) and PMI (2019). This is an important success factor for new projects, and it is also very important that stakeholders are involved and very close to the project;

2. Standardized enterprise portfolio decision making connected to diversified execution and delivery

The market shows us clear distinctions between standardizing strategic portfolio decision making and management and diversifying execution methods and approaches based on time for value. Continuous delivery is driving more PPM leaders to connect aligned strategic business investments with diversified, changing delivery focused on time for value creation (Henderson et al., 2019);

\section{Continuous change}

We are living in a globalized world with fast technology evolution, so Project and Porfolio Managers must be focused to working on a continuous change perspective. The PPM is a very important agent to allow companies to be aligned with innovation and evolution, maintaining a diversified offer without concentrating on just a few items, as those that do not evolve are unlikely to survive. The Project Manager has an important role in this respect. Bolick (2019) mentioned the importance of promoting agility and change, related with Project Manager as agents that respond to digital transformation. There were many known companies that disappeared because of lack of innovation. Take, for example, the case of Kodak, a large American multinational in the area of photography, which, by not investing on the digital, keeping its bet on 
traditional film, ended up disappearing from the market. Therefore, innovation is fundamental in a context of an increasingly global economy and the need to evolve to levels of greater competitiveness (Cabeças, 2018);

4. Supporting the shift from project-based management to digital-product-based management

The shift from project-based management to digital-product-based management is already a reality. This implies a need to continue to evolve towards collaborative delivery teams and it is necessary to give support resourced digital product management (Henderson et al., 2019). Digital-product-based management will bring advantages over the competition that will continue to bet only on a traditional projectbased management logic;

5. Funding and resourcing agile investments at the portfolio level

The evolution of technology and rapid change is leading companies to make strong investments in digital and agile transformations, in order to achieve an expected result. For this to happen, business and technology teams need to be closely connected and aligned, and these investments must be considered from a portfolio perspective;

6. Funding and resourcing digital products at the portfolio level

Concerning funding and resourcing digital products, it is necessary to adapt the PPM mindset and culture to a global perspective of portfolio level oriented to digital products. As referred by Henderson (2019), we will have more organizations with enterprise project, program or product management office (PMO) focused on integrating digital products and programs;

7. AI-enabled PPM technology, including conversational $\mathrm{AI}$ and machine learning (ML)

PPM leaders try to find modern technologies to optimize and support the new roles, responsibilities and delivery methods of their PPM function. Applying AI to PPM-enabling technologies and areas appears to be a promising answer to this struggle, and yet the PPM market is in an embryonic stage as it relates to AIenabled PPM (Henderson et al., 2019);

8. Robotic Process Automation - enabled PPM technology

Demand for the latest digital technologies as robotic process automation is also applying pressure to providers in the PPM market (Henderson et al., 2019).

PPM capabilities identified as essential or critical, also mentioned by Henderson et al. (2019), include the following items:

- Project demand management;

- Project planning and management;

- Time management;

- Resource management;

- Resource capacity planning;

- Project portfolio management;

- Project collaboration;

- Program management;

- Reporting services;

- Security and user management;

- Integration;

- Usability.

As mentioned by the same authors, risk management and change management are also important capabilities but are not specifically measured in our PPM Critical Capabilities research as major items, but they are covered as underlying capabilities of other capabilities included in the previous list.

Because new projects will produce high impacts in society and in environment, it is recommended that Project Managers follow the recommendations of the Global GPM, in terms of respect for the 5 "P's". We are living in a world increasingly globalized, in which resources are limited, such as drinking water, coal and sand, that are threatened by their overuse, poor distribution and by climatic factors. The increase in pollution and the global planet warming must also be considered as a very serious concern. In a recent estimate by the Global Footprint Network, to maintain the same current consumption pattern, we would need to have 1.75 planet Earth, but we only have one. 


\section{Conclusions}

We are going through a phase of great transformation in everything related to technology, the way business is conducted and how work is carried out. The availability of technologies, using artificial intelligence, Internet of Things, Big Data and Robotic, will continue to enhance the creation of new products that tend to improve the efficiency of humans, society, and organizations. The fourth industrial revolution causes changes in the labour market are expected, with the disappearance of some more routine and manual jobs (mainly in industry and agriculture), especially in jobs that require less qualifications, while other jobs will be created, namely associated with the creation, maintenance and administration of new technologies, as well as jobs related to creative intelligence, organizational manipulation, or social intelligence.

Though Industry 4.0 provides benefits, human freedom and confidentiality need to be maintained, special attention should be given to the new ethical issues that arise. Regulation plays a fundamental role in this respect, as well as the correct individual and organizational use of technologies, so that they act as facilitators to individuals and organizations rather than make humans slaves to these technologies. Grey (2016) predicted that solving complex problems, critical thinking, and creativity are the most important skills needed to face the Fourth Industrial Revolution. Emotional intelligence and cultural awareness must also be considered as strongly associated to technical skills.

In the recent period of the covid-19 pandemic, the Fourth Industrial Revolution continues to advance, but now at a faster pace, forcing the anticipation of strategic and operational decisions on the use of artificial intelligence, advanced robotics, big data and business intelligence. The use of new technologies in the implementation of telework already allows for a significant number of employees of companies in the services area to work from home. Today, a Project Manager is already able to manage projects without being physically present, using Project Management support tools and videoconferencing systems, which allow for project planning and control at a distance and conducting online contact sessions with the project participants. In the industry, with intelligent robotics, many tasks can also be performed without workers being physically present. In the health sector, the evolution has been remarkable, for example, imaging exams can already be diagnosed online by doctors working from their homes, through their personal computers, the same being also true for surgical intervention supported by robotic systems. There are studies and experiences on computerized prosthesis commanded by the human brain being created and intelligent artificial organs being produced. Intelligent buildings, offices, private homes, vehicles and agriculture are other examples of recent evolution.

The Fourth Industrial Revolution implies changes in the way projects are managed and requires Project Managers to adapt to the new needs and expectations of the sector, responding to the development of new technologies. PMI (2019), highlights that the approaches used by PMTQ Innovators Versus the PMTQ Laggards, using a variety of project management approaches, lead to better results, considering that organizations which are PMTQ Innovators are better prepared to take the lead on project outcomes. Their projects are more likely to meet their original goals and be delivered on time and within budget while reducing scope creep and outright failure, leading to success.

Project Managers are agents of digital transformation and will have to be aligned with their organization's strategy. More than technical specialists in the area of their projects, Project Managers must be able to take advantage of the data and information available using Business Intelligence and Big Data. They should also use the new capabilities offered by artificial intelligence tools to support all Project Management activities, stressing the importance of QTGP. There are, therefore, new technological challenges which Project Managers must meet, but they cannot lose sight of the importance of the five "P's", People, Planet, Prosperity, Processes and Products, taking care of the planet, following ethical and sustainability principles, and the future is already happening. 


\section{References}

Aoun, J. E. (2017). Robot-Proof: Higher Education in the Age of Artificial Intelligence. USA: MIT Press.

Bolick, C. (2019). How can Project Managers Prepare for the Fourth Industrial Revolution?. Northeastern University, Boston, https://www.northeastern.edu/graduate/blog/project-management-fourthindustrial-revolution/, 2019.

Cabeças, A. (2018). Apontamentos de Gestão de Projetos. Lisboa: A. Angels.

Febbraco, A. et. al. (2019). One-Way Car-Sharing Profit Maximization by Means of User-Based Vehicle Relocation. IEEE Transactions on Intelligent Transportation Systems, 20(2), pp. 628-641.

Ford, M. (2015). Rise of the robots: technology and the threat of a jobless future. New York: Basic Books, a member of the Perseus Books Group.

Goleman, D. (1995). Emotional intelligence. New York: Bantam Books.

Goodwin, T. (2015). In the Age of Disintermediation the Battle is all for the Consumer Interface. TechCruncb, http://techcrunch.com/2015/03/03/in-the-age-of-disintermediation-thebattle-is-allfor-the-customer-interface/, 2015.

GPM Global (2019). The GPM P5 ${ }^{\text {TM }}$ Standard for Sustainability in Project Management. Version 2.0, USA.

Grey, A. (2016). The 10 skills you need to thrive in the Fourth Industrial Revolution. World Economic Forum. https://www.weforum.org/agenda/2016/01/the-10-skills-you-need-to-thrive-in-thefourth-industrial-revolution/

Griffiths, F. and Ooi, M. (2018). The Fourth Industrial Revolution - Industry 4.0 and IoT. IEEE Instrumentation and Measurement Magazine, 21(6), pp. 29-43.

Henderson, A.; Stang, D.; Schoen, M. (2019). Magic Quadrant for Project and Portfolio Management. Gartner, $\quad$ Published $21 \quad$ May $2019 \quad$ - $\quad$ ID https://www.gartner.com/en/documents/3917095/magic-quadrant-for-project-and-portfoliomanagement

IPMA (2015). "Individual Competence Baseline for Project, Programme Portfolio Management". 4th version, International Project Management Association, IPMA ICB, Switzerland, ISBN 978-9492338-00-6, 2015.

IPMA (2016). "Organisational Competence Baseline for Developing Competence in Managing by Projects". Version 1.1, International Project Management Association, IPMA Global Sandard, IPMA OCB, Switzerland, ISBN 978-94-92338-07-5, 2016.

Harold (2006). "Project Management, A Systematic approach to planning, Scheduling and controlling”.

Kerzner, H. (2014). "Surviving Disasters in Project Management: An Interview with Dr. Harold Kerzner", https://www.huffpost.com/entry/surviving-disasters-in-pr_b_4590442, 2014.

Keynes, J. M. (1930). Economic possibilities for our grandchildren. Essays in Persuasion, New York: Harcourt Brace, pub. 1932, pp. 358-373, 1930.

Kunze, L, Hawes, N., Duckett, T., Hanheide, M., Krajnik, T. (2018). Artificial Intelligence for Long-Term Robot Autonomy: A Survey. IEEE Robotics and Automation Letters, 3(4), pp. 4023-4030, https://ieeexplore.ieee.org/document/8421618.

Mariani, M. (2017). Big IoT Data Analytics: Architecture, Opportunities, and Open Research Challenges. IEEE Access, 5, pp. 5247-5261.

Marques da Silva, M. and Monteiro, F. (2014), "MIMO Processing for 4G and Beyond: Fundamentals and Evolution", CRC Press Auerbach Publications: ISBN: 9781466598072, FL, USA, June 2014

Marques da Silva, M. and Dinis, M. (2017). A Simplified Massive MIMO Implemented with Pre or PostProcessing. Physical Communications, Elsevier, Physical Communication-Elsevier, 1(1), pp. 1-12. http://dx.doi.org/10.1016/j.phycom.2017.06.002

Marques da Silva, M. et. al. (2018), On the Contribution of 5G Communications to Industry 4.0. Proceedings of Eighth International Conference on Business Sustainability 2018, Póvoa de Varzim, Portugal, 7-9 November 2018 
Marques da Silva, M. (2019). "Os desafios da 4므 Revolução Industrial na Empregabilidade e no apoio às Pessoas Vulneráveis", Valores, Ética e Responsabilidade (VER), 6 December 2019, accessed on 26 February 2020 through https://www.ver.pt/os-desafios-da-4a-revolucao-industrial-naempregabilidade-e-no-apoio-as-pessoas-vulneraveis/.

Melanima, L. (2018). "Quarta Revolução Industrial e o Gestor de Projetos 4.0”. https://www.linkedin.com/pulse/quarta-revolu\%C3\%A7\%C3\%A3o-industrial-e-o-gestor-deprojetos-40-lucas/. 2018.

Meyer, T. (2020). "IDC FutureScape: Western Europe Digital Leader 2020 Predictions". https://idc.pt/futurescape/wp-content/uploads/2020/02/IDC-Thomas-Meyer-IDC-FutureScape2020.pdf. IDC FutureScape 2020, Lisbon, IDC Research, 2020.

OECD (2018), "Putting faces to the risk of automation", Policy Brief on the Future Work, OECD Publishing, Paris, 2018, available from https://www.oecd.org/employment/Automation-policy-brief2018.pdf

Project Management Institute (2013). "A Guide to the Project Management Body of Knowledge: PMBOK Guide". Fifth Edition, Project Management Institute.

- (2018). "Pulse of the Profession 2018 - Success in Disruptive Times". PMI, 2018.

- (2019). "PMI's Pulse of the Profession. The Future of Work Leading the Way With PMTG". Project Management Institute, 2019.

Price Waterhouse \& Coopers (2017). “A 4a Revolução Industrial”. Grande Consumo em 1/07/2017. https://www.pwc.pt/pt/sala-imprensa/press-room/2017/4-revolucao-industrial.html, 2017.

KPMG; AIPM; IPMA (2019). "The Future of Project Management: Global Outlook 2019". Project Management Survey 2019, KPMG International Cooperative, Australian Institute of Project Management, International Project Management Association. November 2019.

Rainai, Z., Kocsis, I. (2017). "Labor market risks of industry 4.0, digitization, robots and AI", Proc. of 2017 IEEE 15th International Symposium on Intelligent Systems and Informatics (SISY), Subotica, Serbia, September 2017.

Rappaport, T.S. et. al. (2013). Millimeter Wave Mobile Communications for 5G Cellular: It Will Work! Access, IEEE , 1, pp.335-349.

Schwab, K. (2016). The fourth Industrial Revolution. World Economic Forum.

Wagner, R. (2017). The Fourth Industrial Revolution ... and what it means for project management! International Project Management Association, IPMA. https://www.ipma.world/fourth-industrialrevolution-means-project-management/, pub. 13 February 2017.

Zhou, K. et. al. (2015). Industry 4.0: Towards future industrial opportunities and challenges. Proc. of 2015 12th International Conference on Fuzzy Systems and Knowledge Discovery (FSKD), Zhangjiajie, China, Aug. 2015. 